\title{
Recurrent Transient Ischemic Attacks in a 48-Year-Old Patient With an Undiagnosed Ebstein's Anomaly: A Case Report
}

\author{
Nuno Correia ${ }^{\mathrm{a}, \mathrm{c}}$, Ana Calóa, Guilherme Gama ${ }^{\mathrm{a}, \mathrm{b}}$, Luísa Fonseca ${ }^{\mathrm{a}, \mathrm{b}}$, Goreti Moreira ${ }^{\mathrm{a}, \mathrm{b}}$
}

\begin{abstract}
Ebstein's anomaly is a rare congenital malformation of the heart characterized by apical displacement of the septal and posterior tricuspid valve leaflets, leading to atrialisation of the right ventricle with a variable degree of malformation and displacement of the anterior leaflet. Its presentation depends on the severity of the anomaly. Mild forms are often undiagnosed until adulthood due to its benign course. Importantly, interatrial communications are present in $80 \%$ of the patients with EA through which a paradoxical embolism may occur whenever a right-to-left shunt exists. The authors describe a case of a 47-year-old white man that presented with acute recurrent transitory ischemic brain attacks and progressive exertional dyspnea. A brain CT scan revealed infarcts in multiple vascular territories. Echocardiographic studies revealed an Ebstein's anomaly with a right-to-left shunt through an interatrial communication and severe right heart failure. Doppler study of the cervical and extremities' vessels was negative for a possible thrombotic source. A diagnosis of transient ischemic attacks presumably secondary to paradoxical embolism with unknown source was established. The patient was successfully submitted to heart surgery and improvement of symptoms and heart function was observed. At follow-up he remains well and without further neurological events.
\end{abstract}

Keywords: Ebstein's anomaly; Interatrial communication; Paradoxical embolism; Transient ischemic attacks

\footnotetext{
Manuscript accepted for publication November 24, 2011

${ }^{a}$ Internal Medicine Service, Hospital de Sao Joao, Alameda Prof. Hernani Monteiro 4200 - 319 Porto, Portugal

${ }^{\mathrm{b}}$ Stroke Unit - Internal Medicine Service, Hospital de Sao Joao, Alameda Prof. Hernani Monteiro 4200 - 319 Porto, Portugal

${ }^{\mathrm{c} C}$ orresponding author: Nuno Correia. Email: nunovox@gmail.com
}

doi: $10.4021 / \mathrm{jmc} 439 \mathrm{w}$

\section{Introduction}

Ebstein's anomaly (EA) is a rare congenital malformation of the heart characterized by apical displacement of the septal and often posterior tricuspid valve leaflets, leading to "atrialisation" of the right ventricle with a variable degree of malformation and displacement of the anterior leaflet. The prevalence of EA is about 1 in 50,000 to 200,000 with no gender predilection and it accounts for less than $1 \%$ of all congenital heart disease $[1,2]$. It is estimated that approximately $5 \%$ of the patients survive beyond the age of 50 years [3].

The clinical presentation varies widely from asymptomatic to severe symptoms according to the degree anatomic variation and heart failure. Severe disease leads to fetal or neonatal death [4]. Mild forms are often undiagnosed until adulthood due to its benign course and survival has been reported until the ninth decade $[1,5]$.

We present the case of a patient in whom this rare congenital heart malformation was only diagnosed in adulthood in the context of the investigation of recurrent acute stroke manifestations. Discussion of the problems associated with this disease and its treatment is supported by an up-to-date literature review.

\section{Case Report}

A 48-year-old man presented to the Emergency Room at our hospital complaining of sudden episodes of right-sided hemiparesis and hemi-hypoesthesia lasting less than 30 minutes and occurring three times within the last 24 hours. Additionally he reported increasing exertional dyspnea in the past few months.

He was a former intravenous drug user and had a 24 pack-year smoking history. Besides methadone maintenance treatment, he was not taking any other medications. He had a "heart murmur" and "respiratory problems" known since childhood without further investigation. At the age of 43 he was admitted in another hospital due to stroke and discharged from the ward with a left side hemiparesis from which he 


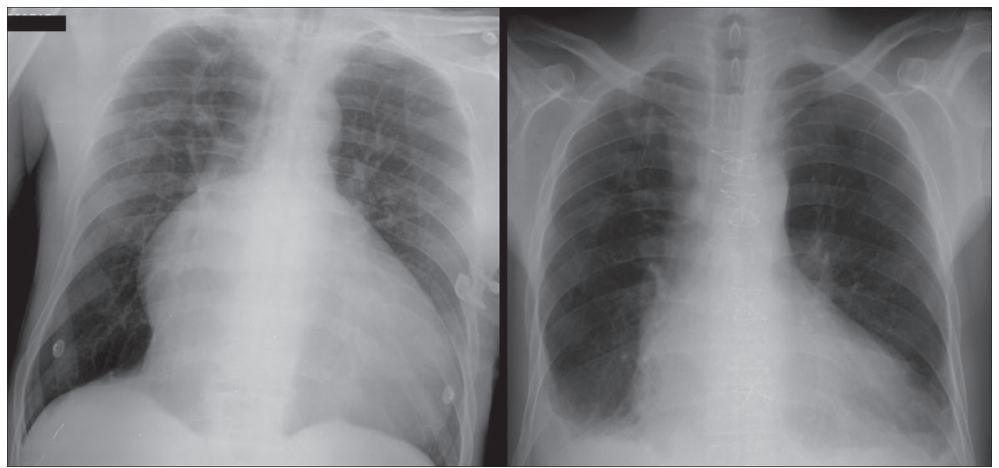

Figure 1. Chest radiograph. Left figure: chest X-ray on Emergency Room's admission revealed significant cardiomegaly, prominent right atrium and straight left heart border. Right figure: imaging at postoperative image showed close-to-normal anatomical configuration of the heart as a result of major heart plasty.

fully recovered. No clinical data was available from that admission. His family history was negative for congenital heart disorders.

At the Emergency Department, his neurological examination was unremarkable. He had a blood pressure of $164 / 110 \mathrm{mmHg}$, pulse rate of 82 beats/min, respiratory rate of 28 breaths $/ \mathrm{min}$ and oxygen saturation of $92 \%$ on room air. A grade 3/6 holosystolic heart murmur was heard at the left sternal border; he had a positive jugular venous distension $(5 \mathrm{~cm})$, no lung rales or peripheral oedemas, and liver was palpable $2 \mathrm{~cm}$ below the right costal margin with an estimated span of $10 \mathrm{~cm}$. He had no cyanosis, clubbing or any other signs of respiratory failure.

Chest X-ray suggested a right-sided heart enlargement

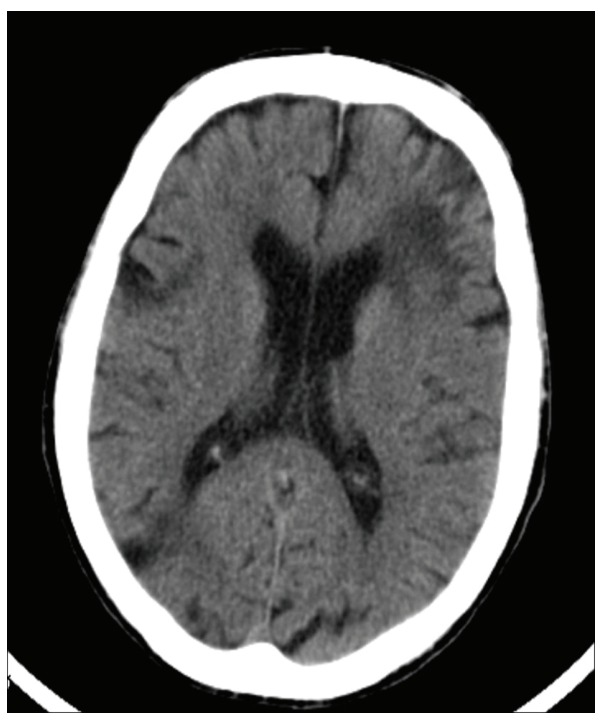

Figure 2. Head computed tomography scan revealed an extensive left frontal corticosubcortical ischemic lesion, and other significant ischemic foci at the head of the right caudate nucleus. Sequelae of focal ischemic lesions were additionally seen scattered through the brain and cerebellum. and lung congestion (Fig. 1). Laboratorial results showed an elevated BNP value $(539.3 \mathrm{pg} / \mathrm{mL}$; normal value $<100$ $\mathrm{pg} / \mathrm{mL}$ ) and a mild cholestatic pattern of liver dysfunction. The biomarkers of myocardial ischemia, lipid profile, homocysteine levels and the autoimmunity panel were normal and screening tests for syphilis, HIV, HBV and HCV were negative.

The electrocardiogram showed a normal sinus rhythm, with right atrial abnormality, QS pattern in DIII and aVF, and poor R-wave progression on pre-cordial leads.

Computed tomography scan of the brain showed multiple ischemic lesions and moderate atrophy of the brain and cerebellum (Fig. 2).

The patient was admitted into the Stroke Unit for further investigation and treatment.

A transthoracic echocardiogram revealed a severe right atrial aneurismatic dilatation and abnormal asymmetric tricuspid valve with an apical implantation of the septal leaflet $\left(8.1 \mathrm{~cm} / \mathrm{m}^{2}\right)$, with a sail-like structure and severe dilation of the annulus, with dysplastic and redundant leaflets, aneurismatic wall of the interatrial septum with a radium of $10-11 \mathrm{~mm}$, with abnormal septal movement; pulmonary artery systolic pressure estimated at $44(24+20) \mathrm{mmHg}$, resulting in severe right heart failure; passage of agitated saline contrast from right to left chambers suggested an interatrial communication (Fig. 3). Additionally, a two-dimensional colour-Doppler transesophageal echocardiogram unveiled a $2 \mathrm{~mm}$ interatrial communication, with a discrete right-to-left shunt, during systole and early diastole, at the anterosuperior portion of the septum (Fig. 4).

These echocardiographic findings were compatible with Ebstein's abnormality and raised the hypothesis of a paradoxical embolic event due to the evidence of an interatrial communication. Doppler ultrasonographic study of carotid, vertebral, transcranial, and extremities vessels was unremarkable.

The patient was treated with warfarin, diuretics, angio- 


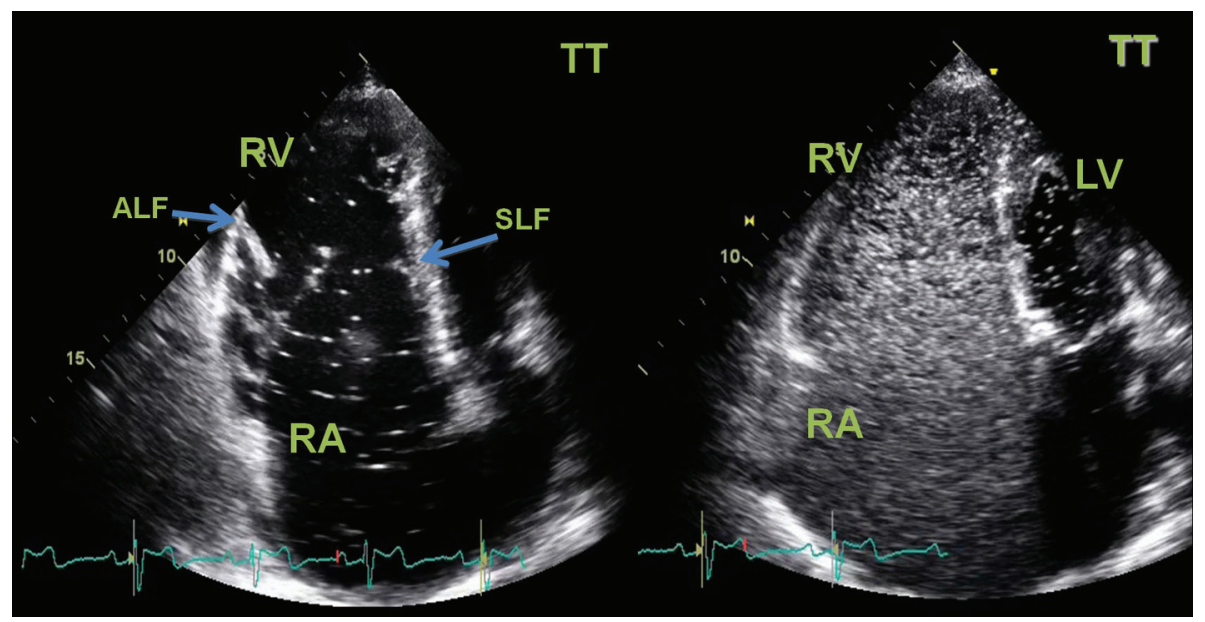

Figure 3. Two-dimensional transthoracic (TT) echocardiogram. Left image: apical chamber view showed a severe right atrial aneurismatic dilatation, an asymmetric tricuspid valve with a "sail-like" structure, tethering of the septal leaflet with distal implantation at $8.1 \mathrm{~cm} / \mathrm{m}^{2}$ (atrialized right ventricle). The tricuspid valve leaflets were dysplastic and major defect of central coaptation was observed resulting in severe tricuspid failure. Right ventricle systolic function was severely compromised. Diastolic flattening of interventricular septum and paradoxical septal motion was seen in favour of right ventricular overload. Left chambers had normal dimensions and left ventricle systolic function was preserved. No vegetations or thrombus were seen. Right Image: passage of agitated saline contrast from right to left chambers through an interatrial communication was documented (white spots on LV area) in favor of the presence of a right-to-left shunt.

RA: right atrium; RV: right ventricle; LA: left atrium; LV: left ventricle; SLF: septal leaflet; ALF: anterior leaflet.

tensin-converting enzyme inhibitors and beta-blockers. After clinical stabilization he was submitted to a complex heart surgical treatment that involved ventricule plasty of the heart and reconstruction of the triscuspide valve.

The post-operative course was favorable. One year later, the patient presented mild exertional dyspnea with no additional complaints. Echocardiogram revaluation showed mild tricuspid insufficiency, with no stenosis of the valve ring,

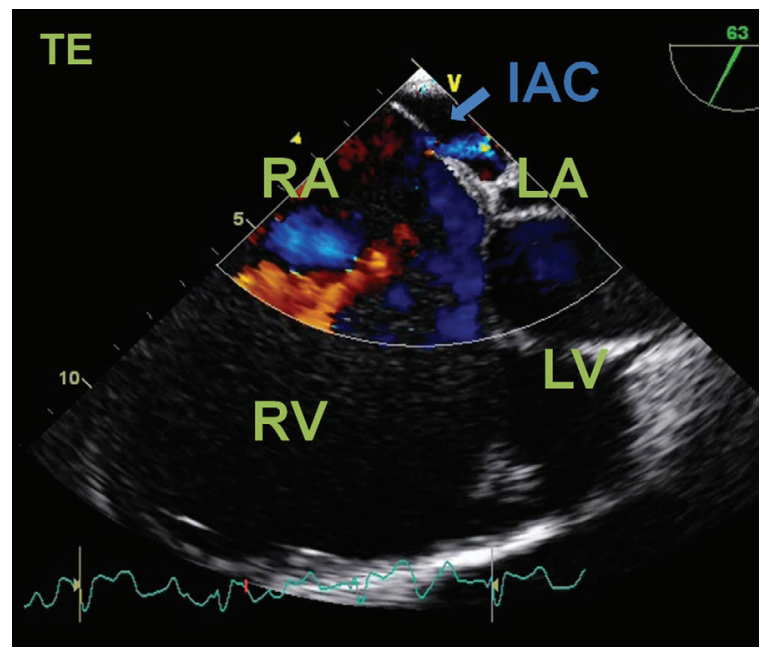

Figure 4. Transesophageal echocardiogram. Four-chamber color flow view showing a right-to-left shunt through an interatrial communication (IAC). RA: right atrium; RV: right ventricle; LA; left atrium; LV: left ventricle. with mild compromise of the right ventricle function, and a left ejection fraction of $65 \%$.

\section{Discussion}

Ebstein's anomaly is a malformation of the right heart characterized by an apical displacement of both the septal and the posterior tricuspid leaflets, exceeding $20 \mathrm{~mm}$ or $8 \mathrm{~mm} /$ $\mathrm{m}^{2}$ in adults $[6,7]$. As a consequence, the right heart may be divided in three components including the true right atrium, the functional right ventricle (RV) and an intervening zone that is anatomically ventricular but functionally right atrial (atrialized RV) [8]. The thin wall of the atrialized RV may result in an aneurysm between the anatomic tricuspid annulus and the apically displaced posterior leaflet [9]. Almost eighty percent of the EA patients have an interatrial communication and various additional cardiac abnormalities are often present [2].

The cause of EA is not well understood. The occurrence of families with EA suggests the possibility of defects in genes contributing to malformations of the tricuspid valve and it is thought to implicate a multifactorial genetic trait $[10,11]$. Others have proposed the EA gene might be located in the chromosome 9 [12]. Nongenetic causes such as intrauterine lithium exposure and intrauterine infections have been pointed out $[13,14]$.

The clinical presentation depends on the age at presentation, anatomic severity, hemodynamics, and degree of right- 
to-left interatrial shunting, if present [15]. The most commons symptoms in adults are exercise intolerance (dyspnea and fatigue) and symptomatic supraventricular arrhythmias. Patients with mild apical displacement and normal function of the tricuspid valve may remain asymptomatic and survive to the ninth decade has been reported [5]. However, patients may die or become symptomatic at any age. At the extreme of marked tricuspid leaflet displacement, severe regurgitation, elevated right atrial pressures, and significant right-to-left interatrial shunting through an interatrial communication may develop and manifest as right-sided heart failure [4]. Palpitations secondary to atrial tachyarrhythmia are present in 20 to $30 \%$ of cases due to the dilated right atrium, the presence of Wolff-Parkinson-White syndrome or a concealed bypass tract $[16,17]$. Paradoxical embolism or brain abscess are important death causal factors, mainly in patients older than 50 years.

Doppler echocardiography is the method of choice for the diagnosis of EA and associated heart defects and stratification of the degree of anatomic and functional defects [18]. Echocardiographic measurement of the ratio of the combined area of the right atrium and atrialized right ventricle to that of the functional right ventricle and left heart in a four-chamber view at end-diastole has been used for classification into four different grades with increasing severity $[19,20]$. Our patient had a grade 3 EA. Right-to-left shunting of blood through defects of the interatrial septum are best visualized by color flow imaging or agitated saline contrast. Echocardiography has largely obviated cardiac catheterization. Cine MRI may also be helpful in providing a better assessment of both right and left ventricular size and function when echocardiography images are limited and to address areas of delayed myocardial enhancement after administration of contrast agents [21-23]. These areas suggest scarring or fibrosis and can occur in myocardial infarction and in a variety of other disorders, such as inflammatory or infectious diseases of the myocardium, cardiomyopathies, cardiac neoplasms, congenital or genetic cardiac conditions, as well as after cardiac interventions [24].

Recurrent transient ischemic attacks may be caused by embolic processes in approximately $25 \%$ of the ischemic strokes [25]. Paradoxical embolus is a rarely diagnosed cause of arterial ischemia and is considered the major cause of cerebral ischemic events in young patients [26, 27]. It is usually described in association with a patent foramen ovale in the context of cryptogenic strokes [28-30]. Due to the frequent presence of an interatrial communication (atrial septal defect or patent foramen ovale) patients with EA are at risk of paradoxical embolization, cerebral ischemic attacks, brain abscesses and sudden death [18, 31]. The embolus can originate in veins of the lower extremities, in pelvic veins, in an atrial septal aneurysm, or from a clot around the edges of a patent foramen ovale [32-34]. However in many cases the embolic source in not identified, such as in our patient.
Indications for heart surgery have included symptoms, deteriorating exercise capacity, New York Heart Association functional class III or IV heart failure, cyanosis, paradoxical embolism, progressive cardiac enlargement, severity of tricuspid regurgitation, and atrial of ventricular arrhythmias. Observation has been recommended for asymptomatic patients with low normal exercise tolerance, no right-to-left shunting, and only mild cardiomegaly [35, 36]. Operative repair usually includes tricuspid valve reconstruction with plication of the atrialized portion of the right ventricle (and correction of co-existing congenital septum defects or aneurism), utilizing tricuspid valvuloplasty or replacement [18].

Patients with EA should only be repaired by surgeons with an interest in and experience with congenital heart disease, ideally with specific experience in this operation. Every effort should be made to preserve the native tricuspid valve [35]. Since each heart with EA is different according to the anatomical variability, numerous techniques of repair have been described $[19,36]$. Recent surgical techniques developments may extend classical surgical indications to asymptomatic or mildly symptomatic patients in order to prevent complications such as arrhythmia and ventricular dysfunction [36].

In conclusion, the presented case underlines the possible late presentation of Ebstein's anomaly in adulthood as recurrent brain ischemic attacks. Ebstein's anomaly can remain undiagnosed until adulthood if the right ventricle is hemodynamically well functioning. Stroke may occur due to paradoxical embolism by an interatrial communication. Heart surgical treatments usually considered when patients become symptomatic. However, recent surgical techniques may allow an efficient "preventive surgical treatment" in asymptomatic patients at an earlier stage of this heart malformation.

\section{Consent}

Written informed consent was obtained from the patient for publication of this case report.

\section{List of Abbreviations}

EA: Ebstein's anomaly; IAC: interatrial communication; MRI: magnetic resonance imaging.

\section{Competing Interests}

The authors declare that they have no competing interests.

\section{Authors' Contributions}


Nuno Correia was involved in conception, data acquisition and drafting the manuscript. Ana Caló contributed with important literature review and helped to draft the manuscript. Guilherme Gama, Luísa Fonseca, and Goreti Moreira made substantial intellectual contributions to drafting the manuscript and revising it critically for important intellectual content. All authors read and approved the final manuscript.

\section{References}

1. Dearani JA. Behavior of Ebstein's anomaly. Cardiology. 2010;117(2):88-89.

2. Attenhofer Jost CH, Connolly HM, Dearani JA, Edwards WD, Danielson GK. Ebstein's anomaly. Circulation. 2007;115(2):277-285.

3. Keith, J.D., R.D. Rowe, and P. Vlad, Heart disease in infancy and childhood. 3d ed. 1978, New York: Macmillan. xvii, $1083 \mathrm{p}$.

4. Celermajer DS, Bull C, Till JA, Cullen S, Vassillikos VP, Sullivan ID, Allan L, et al. Ebstein's anomaly: presentation and outcome from fetus to adult. J Am Coll Cardiol. 1994;23(1):170-176.

5. Adams JC, Hudson R. A case of Ebstein's anomaly surviving to the age of 79. Br Heart J. 1956;18(1):129-132.

6. Shiina A, Seward JB, Tajik AJ, Hagler DJ, Danielson GK. Two-dimensional echocardiographic--surgical correlation in Ebstein's anomaly: preoperative determination of patients requiring tricuspid valve plication vs replacement. Circulation. 1983;68(3):534-544.

7. Gussenhoven EJ, Stewart PA, Becker AE, Essed CE, Ligtvoet KM, De Villeneuve VH. "Offsetting" of the septal tricuspid leaflet in normal hearts and in hearts with Ebstein's anomaly. Anatomic and echographic correlation. Am J Cardiol. 1984;54(1):172-176.

8. Frescura C, Angelini A, Daliento L, Thiene G. Morphological aspects of Ebstein's anomaly in adults. Thorac Cardiovasc Surg. 2000;48(4):203-208.

9. Benson LN, Child JS, Schwaiger M, Perloff JK, Schelbert HR. Left ventricular geometry and function in adults with Ebstein's anomaly of the tricuspid valve. Circulation. 1987;75(2):353-359.

10. McIntosh N, Chitayat D, Bardanis M, Fouron JC. Ebstein anomaly: report of a familial occurrence and prenatal diagnosis. Am J Med Genet. 1992;42(3):307-309.

11. Emanuel R, O’Brien K, Ng R. Ebstein's anomaly. Genetic study of 26 families. Br Heart J. 1976;38(1):5-7.

12. Andelfinger G, Wright KN, Lee HS, Siemens LM, Benson DW. Canine tricuspid valve malformation, a model of human Ebstein anomaly, maps to dog chromosome 9. J Med Genet. 2003;40(5):320-324.

13. Allan LD, Desai G, Tynan MJ. Prenatal echocardiographic screening for Ebstein's anomaly for mothers on lithium therapy. Lancet. 1982;2(8303):875-876.
14. Siebert JR, Barr M, Jr., Jackson JC, Benjamin DR. Ebstein's anomaly and extracardiac defects. Am J Dis Child. 1989;143(5):570-572.

15. Riaz, K. (2011) Ebstein Anomaly.

16. Watson H. Natural history of Ebstein's anomaly of tricuspid valve in childhood and adolescence. An international co-operative study of 505 cases. Br Heart J. 1974;36(5):417-427.

17. Lev M, Gibson S, Miller RA. Ebstein's disease with Wolff-Parkinson-White syndrome; report of a case with a histopathologic study of possible conduction pathways. Am Heart J. 1955;49(5):724-741.

18. Mulder, B., Ebstein's anomaly in the adult patient. Netherlands Heart Journal, 2003. 11(5): p. 195-197.

19. Attenhofer Jost CH, Connolly HM, Edwards WD, Hayes D, Warnes CA, Danielson GK. Ebstein's anomaly - review of a multifaceted congenital cardiac condition. Swiss Med Wkly. 2005;135(19-20):269-281.

20. Dearani JA, Danielson GK. Congenital Heart Surgery Nomenclature and Database Project: Ebstein's anomaly and tricuspid valve disease. Ann Thorac Surg. 2000;69(4 Suppl):S106-117.

21. Yalonetsky S, Tobler D, Greutmann M, Crean AM, Wintersperger BJ, Nguyen ET, Oechslin EN, et al. Cardiac magnetic resonance imaging and the assessment of ebstein anomaly in adults. Am J Cardiol. 2011;107(5):767773.

22. Eustace S, Kruskal JB, Hartnell GG. Ebstein's anomaly presenting in adulthood: the role of cine magnetic resonance imaging in diagnosis. Clin Radiol. 1994;49(10):690-692.

23. Fisher MR, Lipton MJ, Higgins CB. Magnetic resonance imaging and computed tomography in congenital heart disease. Semin Roentgenol. 1985;20(3):272-282.

24. Vogel-Claussen J, Rochitte CE, Wu KC, Kamel IR, Foo TK, Lima JA, Bluemke DA. Delayed enhancement MR imaging: utility in myocardial assessment. Radiographics. 2006;26(3):795-810.

25. Arboix A, Massons J, Garcia-Eroles L, Comes E, Balcells M, Oliveres M. Recurrent ischemic stroke. Study of 605 patients. Med Clin (Barc). 2011;137(12):541-545.

26. Meister SG, Grossman W, Dexter L, Dalen JE. Paradoxical embolism. Diagnosis during life. Am J Med. 1972;53(3):292-298.

27. Kuhl HP, Hoffmann R, Merx MW, Franke A, Klotzsch C, Lepper W, Reineke T, et al. Transthoracic echocardiography using second harmonic imaging: diagnostic alternative to transesophageal echocardiography for the detection of atrial right to left shunt in patients with cerebral embolic events. J Am Coll Cardiol. 1999;34(6):1823-1830.

28. Lamy C, Giannesini C, Zuber M, Arquizan C, Meder JF, Trystram D, Coste J, et al. Clinical and imaging findings in cryptogenic stroke patients with and without patent 
foramen ovale: the PFO-ASA Study. Atrial Septal Aneurysm. Stroke. 2002;33(3):706-711.

29. Overell JR, Bone I, Lees KR. Interatrial septal abnormalities and stroke: a meta-analysis of case-control studies. Neurology. 2000;55(8):1172-1179.

30. Di Tullio M, Sacco RL, Gopal A, Mohr JP, Homma S. Patent foramen ovale as a risk factor for cryptogenic stroke. Ann Intern Med. 1992;117(6):461-465.

31. Alexander, R.S., RC. Fuster, V., Hurst's The Heart. 1998, New York: McGraw-Hill. 2019-20.

32. Lethen H, Flachskampf FA, Schneider R, Sliwka U, Kohn G, Noth J, Hanrath P. Frequency of deep vein thrombosis in patients with patent foramen ovale and ischemic stroke or transient ischemic attack. Am J Cardiol. 1997;80(8):1066-1069.

33. Cramer SC, Rordorf G, Maki JH, Kramer LA, Grotta JC, Burgin WS, Hinchey JA, et al. Increased pelvic vein thrombi in cryptogenic stroke: results of the Paradoxical Emboli from Large Veins in Ischemic Stroke (PELVIS) study. Stroke. 2004;35(1):46-50.
34. Mas JL, Arquizan C, Lamy C, Zuber M, Cabanes L, Derumeaux G, Coste J. Recurrent cerebrovascular events associated with patent foramen ovale, atrial septal aneurysm, or both. N Engl J Med. 2001;345(24):1740-1746.

35. Bonow RO, Carabello BA, Chatterjee K, de Leon AC, Jr., Faxon DP, Freed MD, Gaasch WH, et al. 2008 Focused update incorporated into the ACC/AHA 2006 guidelines for the management of patients with valvular heart disease: a report of the American College of Cardiology/American Heart Association Task Force on Practice Guidelines (Writing Committee to Revise the 1998 Guidelines for the Management of Patients With Valvular Heart Disease): endorsed by the Society of Cardiovascular Anesthesiologists, Society for Cardiovascular Angiography and Interventions, and Society of Thoracic Surgeons. Circulation. 2008;118(15):e523-661.

36. Dearani, J.A., E. Bacha, and J.P. Da Silva, Cone Reconstruction of the Tricuspid Valve for Ebstein's Anomaly: Anatomic Repair. Operative Techniques in Thoracic and Cardiovascular Surgery, 2008: p. 109-117. 